\title{
Gliptins vs. Milk-derived Dipeptidyl- Peptidase IV Inhibiting Biopeptides: Physicochemical Characterization and Pharmacokinetic Profiling
}

\author{
Gliptinas vs. Biopéptidos Inhibidores de Dipeptidil- \\ Peptidasa IV Derivados de la Leche: Caracterización \\ Fisicoquímica y Perfil Farmacocinético
}

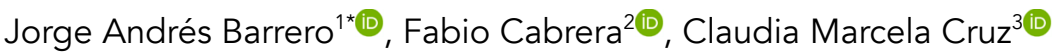

\begin{abstract}
Background: Milk-derived biopeptides have reported in vitro dipeptidyl-peptidase IV (DPPIV) inhibition, suggesting a glycemic-regulatory effect in Type 2 Diabetes Mellitus (T2DM). Nonetheless, the therapeutic application of these nutraceuticals is limited by the scarcity of knowledge regarding their pharmacokinetic profile. Objective: This study aimed to characterize and assess the pharmacokinetics of milk-derived biopeptides. Through an in silico comparative analysis with gliptins, we expected to identify enhanced properties in food-hydrolysates and suitable DPP-IV inhibiting peptides as candidates for T2DM therapy. Methods: A comparison between gliptins and biopeptides was conducted based on in silico evaluation of drug-likeness,

physicochemical properties, pharmacokinetics, and synthetic accessibility. Suitable target proteins for gastrointestinal-absorbable biopeptides were determined as well. Data collection was performed on SwissADME, ADMETlab, DrugBank, SwissTargetPrediction, ChemDes, and BIOPEP-UWM platforms. Statistical analysis was carried out using a one-way ANOVA test. Results: Drug-likeness compliance showed no significant difference between gliptins and biopeptides ( $p>0.05)$ in three out of nine assessed rules, though gastrointestinal-absorbable biopeptides exhibited no significant difference with gliptins in five drug-likeness guidelines. The physicochemical evaluation revealed a significant difference $(p<0.05)$ between both groups, with peptides exhibiting enhanced solubility, flexibility, and polarity. Nine out of thirty-six assessed biopeptides reported being likely gastrointestinal-absorbable molecules, from which six displayed $\geq 30 \%$ predicted bioavailability, two reported CYP450 interactions, and all were determined to be blood confined. Biopeptides showed a slightly lower clearance than gliptins yet counteracted by a significantly lower half-life. Moreover, synthetic accessibility scores indicated higher synthetic ease for biopeptides. In addition, absorbable bioactive peptides reported a considerable binding affinity to DPP-IV and Calpain-I. Conclusions: Compared to gliptins, gastrointestinal-absorbable biopeptides exhibit superior physicochemical properties (higher solubility, flexibility, and polarity), lesser CYP450 interactions, higher synthetic ease, and some reported an important affinity for DPP-IV and Calpain-I. Only a small fraction of milk-derived biopeptides are suitable drug-like compounds and feasible candidates for T2DM therapy; yet, testing their therapeutic potency remains subject to further studies.
\end{abstract}

JOURNAL VITAE

School of Pharmaceutical and Food Sciences ISSN 0121-4004 | ISSNe 2145-2660 University of Antioquia Medellin, Colombia

Filliations

${ }^{1}$ Clinical Biochemistry Research Group, Faculty of Medicine, Universidad Nacional de Colombia. Bogotá,

Colombia.

${ }^{2}$ Department of Science \& Technology Studies, Cornell University. New York

United States of America.

${ }^{3}$ Natural Sciences Department International Baccalaureate Diploma Program - Chemistry Professor, Gimnasio Vermont. Bogotá, Colombia.

*Corresponding Jorge Andrés Barrero jobarreroc@unal.edu.co

Received: 09 June 2021 Accepted: 28 September 2021 Published: 05 October 2021
Keywords: Bioactive peptides; Dipeptidyl-Peptidase IV inhibitors; Pharmacokinetics; Type 2 Diabetes Mellitus. 


\section{RESUMEN}

Antecedentes: Los biopéptidos derivados de la leche han mostrado inhibir la dipeptidil-peptidasa IV (DPP-IV) en ensayos in vitro, lo que sugiere una regulación de la glicemia en la Diabetes Mellitus Tipo 2 (DM2). Sin embargo, su uso terapéutico está limitado por el escaso conocimiento de sus propiedades farmacológicas. Objetivo: Caracterizar y evaluar el perfil farmacocinético de los biopéptidos derivados de la leche. Por medio de un análisis comparativo in silico, se buscó identificar propiedades de carácter superior a las gliptinas en los biopéptidos inhibidores de DPP-IV, así como posibles candidatos a agentes terapéuticos en la DMT2. Métodos: Se llevó a cabo una comparación entre las Gliptinas y los biopéptidos basada en la evaluación in silico de las características "drug-like", propiedades fisicoquímicas, farmacocinética y accesibilidad sintética. Adicionalmente, se determinaron posibles proteínas diana para los biopéptidos de alta probabilidad de absorción gastrointestinal. Los datos se obtuvieron en SwissADME, ADMETlab, DrugBank, SwissTargetPrediction, ChemDes y BIOPEP-UWM. El análisis estadístico se basó en un análisis de varianza (one-way ANOVA test). Resultados: El cumplimiento de las reglas de "drug-likeness" no mostró diferencias significativas entre las gliptinas y los biopéptidos $(p>0.05)$ en tres de las nueve normas evaluadas, empero, los biopéptidos absorbibles no mostraron diferencias significativas con las gliptinas en cinco de estas. La evaluación fisicoquímica reveló una diferencia significativa $(p>0.05)$ entre ambos grupos y una mayor solubilidad, flexibilidad y polaridad para los biopéptidos. Nueve de los treinta y seis biopéptidos estudiados reportaron alta probabilidad de absorción gastrointestinal, de los cuales seis presentaron una biodisponibilidad predicha $\geq 30 \%$, dos reportaron interacciones con el CYP450, y todos mostraron permanecer confinados en sangre. Los biopéptidos mostraron una tasa de aclaramiento inferior a las gliptinas, sin embargo, contrarrestado por una vida-media significativamente menor. Los valores de accesibilidad sintética indicaron una mayor facilidad de síntesis para los biopéptidos. Por último, los biopéptidos absorbibles mostraron una considerable afinidad por la DPP-IV y la Calpaína-I. Conclusiones: Frente a las gliptinas, los biopéptidos absorbibles presentan: propiedades fisicoquímicas superiores (mayor solubilidad, flexibilidad y polaridad), menores interacciones con el CYP450, mayor facilidad de síntesis y algunos una importante afinidad por la DPP-IV y la Calpaína-I. Una mínima fracción de biopéptidos derivados de la leche son candidatos viables para la terapia de DM2; sin embargo, la determinación de su efectividad terapéutica permanece sujeta a futuros estudios.

Palabras clave: Péptidos bioactivos; Inhibidores de la Dipeptidil-Peptidasa IV; Farmacocinética; Diabetes Mellitus Tipo 2.

\section{INTRODUCTION}

Type 2 Diabetes Mellitus (T2DM) associated hyperglycemia accounts for severe long-term vascular impairment responsible for diabetic retinopathy, neuropathy, and kidney disease (1). Fortunately, over the past 20 years, several glycemicregulatory drugs have emerged (2). Among these new alternatives, Dipeptidyl-Peptidase IV (DPP-IV) inhibitors, commonly referred to as gliptins, are often used as a second line for T2DM treatment (3).

After food ingestion, insulin secretion is potentiated by a physiological stimulation mediated by incretin hormones; glucagon-like peptide 1 (GLP-1), and glucose-dependent insulinotropic peptide (GIP). These gut peptides enhance $\beta$-cells glucose sensitivity leading to an augmented insulin release after a rise in glycemia. However, these hormones are promptly hydrolyzed by plasmatic DPP-IV once they reach the bloodstream. As a result, blocking incretin hormones degradation through DPP-IV inhibitors prolongs insulin secretory response in the postprandial state, enhances glycemic regulation, and stimulates satiety $(4,5)$.

Current trends in food chemistry revealed the healthpromoting effects of foodstuffs, acknowledging the therapeutical potential of nutrients - often referred to as nutraceutical properties (6). Nutraceuticals have been linked to beneficial outcomes in several metabolic disorders (7); thus, studying food-derived bioactive compounds is a promising research area. Biologically active peptides released from dietary proteins digestion are known as bioactive peptides (BAPs): oligomeric amino acidic sequences with pleiotropic properties including antidiabetic, antihypertensive, antioxidative, among others.

In vivo studies on diabetic animal models have shown that DPP-IV inhibiting BAPs improve glycemic regulation and enhance insulin sensitivity $(8,9)$. Nevertheless, the evidence is scarce regarding humans. Besides their well-established DPP-IV inhibition, the pharmacokinetic profile of these nutraceuticals remains to be unraveled (10). Recent updates in bioinformatics have led to developing web tools to identify BAPs derived from specific proteins subjected to in silico proteolysis (11) and assess their pharmacokinetic profile based on topological and molecular descriptors before inefficient in vivo assays (12).

The lack of knowledge regarding BAPs' pharmacokinetics limits our understanding of their therapeutic potential. So far, a broad range of oligopeptides with antidiabetic properties have been identified, isolated, and tested through in vitro experimentation; however, no research has yet evaluated the drug-like properties and 
pharmacokinetic parameters for these bioactive compounds. This study aims to assess the pharmacokinetics of milk-derived BAPs (Table 1) through an in silico comparative analysis with gliptins (Figure 1) and identify suitable DPP-IV inhibiting peptides as candidates for T2DM therapy. In addition, elucidating the pharmacological traits of BAPs might serve to determine biochemical features that could be improved to enhance their therapeutic potency.

Table 1. Bioactive peptides obtained from milk proteins digestion catalyzed by pepsin, trypsin and chymotrypsin. Sequence and protein source data taken from (13).

\begin{tabular}{|c|c|c|c|}
\hline $\begin{array}{l}\text { Biopeptide sequence* } \\
\text { (ID) }\end{array}$ & Source & $\begin{array}{l}E C_{50} \\
(\mu \mathrm{M})\end{array}$ & Reference \\
\hline EK (1) & $\begin{array}{c}\alpha \mathrm{S} 1 \text {-casein }{ }^{[c]} \\
\beta \text {-lactoglobulin }{ }^{[b]}\end{array}$ & $3,216.75$ & (14) \\
\hline VPL (2) & $\alpha \mathrm{S} 1$-casein $[c, b]$ & 15.80 & (15) \\
\hline GL (3) & $\beta$-lactoglobulin ${ }^{[c, s, g]}$ & $2,615.03$ & (16) \\
\hline $\mathrm{AL}(4)$ & $\beta$-casein ${ }^{[c, s, b]}$ & 882.13 & (14) \\
\hline SL (5) & $\beta$-casein ${ }^{[c, s, g, b]}$ & $2,517.08$ & (14) \\
\hline $\operatorname{VL}(6)$ & $\begin{array}{c}\beta \text {-casein }{ }^{[c, s, b]} \\
\kappa \text {-casein }[c, s, g, b] \\
\beta \text {-lactoglobulin }{ }^{[b]}\end{array}$ & 74.00 & (17) \\
\hline IPIOY (7) & $\kappa$-casein $[c, s, s, b]$ & 35.20 & (18) \\
\hline VR (8) & $\beta$-lactoglobulin ${ }^{[c, s, g, b]}$ & 826.10 & (19) \\
\hline IPAVF (9) & $\beta$-lactoglobulin $[c, s, g, b]$ & 44.70 & (20) \\
\hline$A Y(10)$ & $\alpha \mathrm{S} 1$-casein $[c, s, g, b]$ & - & (17) \\
\hline GY (11) & $\alpha \mathrm{S} 1$-casein ${ }^{[c, s, g, b]}$ & - & (17) \\
\hline IL (12) & $\begin{array}{c}\alpha \mathrm{S} 1 \text {-casein }{ }^{[c, s, g, b]} \\
\alpha \text {-lactalbumin } \\
{[c, s, q, b]}\end{array}$ & - & $(17)$ \\
\hline PK (13) & $\begin{array}{c}\alpha \mathrm{S} 1 \text {-casein }[c, s, g, b] \\
\beta \text {-casein }[c, s, g, b]\end{array}$ & - & (17) \\
\hline QF (14) & $\kappa$-casein $[c, s, g, b]$ & - & (17) \\
\hline QL (15) & $\alpha \mathrm{S} 1$-casein ${ }^{[c, s, g, b]}$ & - & (17) \\
\hline SK (16) & $\alpha \mathrm{S} 1$-casein ${ }^{[c, s, g, b]}$ & - & (17) \\
\hline VN (17) & $\alpha \mathrm{S} 1$-casein ${ }^{[c]}$ & - & (17) \\
\hline PL (18) & $\alpha \mathrm{S} 1$-casein ${ }^{[c, s, g, b]}$ & - & (21) \\
\hline IN (19) & $\alpha \mathrm{S} 1$-casein ${ }^{[s, g]}$ & - & (17) \\
\hline $\mathrm{IH}(20)$ & $\beta$-casein $[c, s, g, b]$ & - & (17) \\
\hline PF (21) & $\beta$-casein ${ }^{[c, s, g, b]}$ & - & (17) \\
\hline TL (22) & $\kappa$-casein $[c, s, g, b]$ & - & (17) \\
\hline VK (23) & $\beta$-casein $[c, s, g, b]$ & - & (17) \\
\hline VY (24) & $\begin{array}{c}\beta \text {-lactoglobulin }[c, s, g, b] \\
\beta \text {-casein }[c, s, s, b]\end{array}$ & - & (17) \\
\hline $\mathrm{PH}(25)$ & $\kappa$-casein $[c, s, g, b]$ & - & (17) \\
\hline OW (26) & $\kappa$-casein $[c, s, g, b]$ & - & (17) \\
\hline SF (27) & $\begin{array}{c}\alpha \mathrm{S} 1 \text {-casein }{ }^{[c, s, s, b]} \\
\alpha \text {-lactalbumin } \\
{[c, s, g, b]}\end{array}$ & - & (17) \\
\hline PY (28) & $\kappa$-casein ${ }^{[c, s, s, b]}$ & - & (17) \\
\hline $\operatorname{TR}(29)$ & $\kappa$-casein ${ }^{[c]}$ & - & (17) \\
\hline $\mathrm{AH}(30)$ & $\alpha$-lactalbumin $[c, s, g, b]$ & - & (17) \\
\hline
\end{tabular}

\begin{tabular}{|c|c|c|c|}
\hline $\begin{array}{c}\text { Biopeptide sequence* } \\
\text { (ID) }\end{array}$ & Source & $\begin{array}{l}\mathrm{EC}_{50} \\
(\mu \mathrm{M})\end{array}$ & Reference \\
\hline IW (31) & $\alpha$-lactalbumin $[c, s, g, b]$ & - & (17) \\
\hline TK (32) & $\begin{array}{c}\alpha \text {-lactalbumin }[c, s, g, b] \\
\beta \text {-lactoglobulin }[c, s, g, b]\end{array}$ & - & (17) \\
\hline IR (33) & $\beta$-lactoglobulin ${ }^{[c, s, g, b]}$ & - & (17) \\
\hline PM (34) & $\beta$-lactoglobulin ${ }^{[c, s, g, b]}$ & - & (17) \\
\hline$A F(35)$ & $\beta$-lactoglobulin $[c, s, g, b]$ & - & (17) \\
\hline PN (36) & $\begin{array}{c}\kappa \text {-casein }{ }^{[c]} \\
\beta \text {-casein }[c, s, g, b]\end{array}$ & - & (17) \\
\hline
\end{tabular}

*Amino acid sequence presented in a single-letter notation. [] denotates the species isoform from which the BAP is obtained; c: cow (B. taurus), s: sheep ( $O$. aries), g: goat ( $C$. hircus), b: buffalo (B. bubalis).

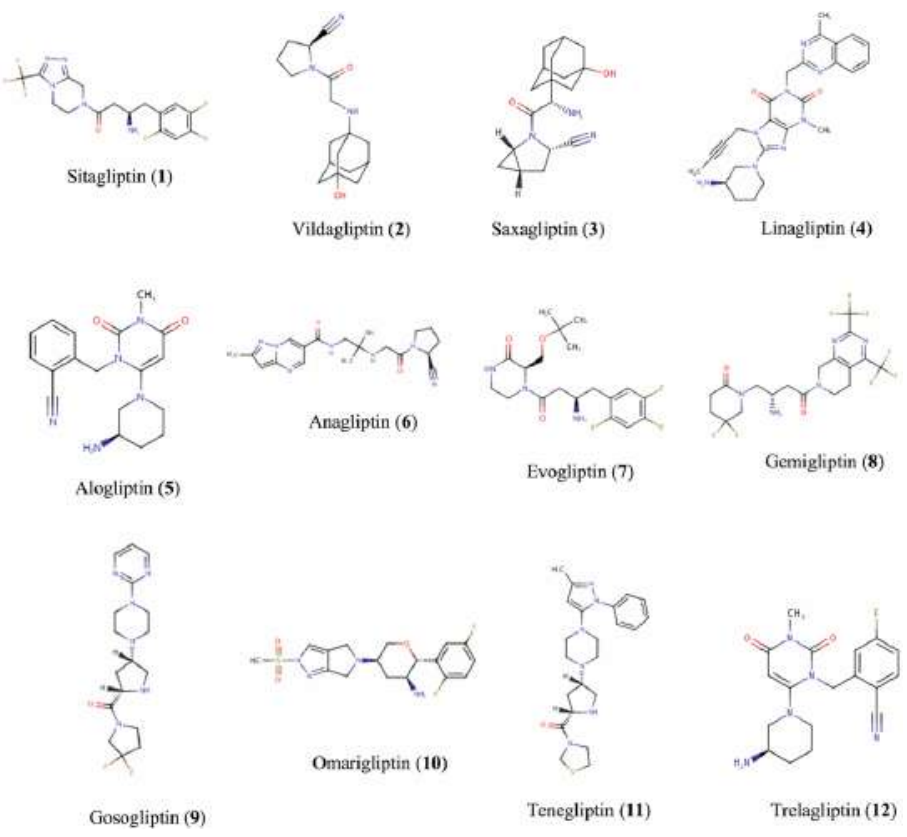

Figure 1. Chemical structure of Gliptins. (ID 1-12)

\section{MATERIALS AND METHODS}

\section{Experimental Design}

As a result of our previous research, thirtysix peptides (Table 1) with DPP-IV inhibiting activity were obtained from milk proteins through simulated gastrointestinal digestion (13). In this paper, formerly characterized milk-derived DPP-IV inhibiting BAPs were subjected to a comparative study with a group of twelve conventional DPP-IV inhibiting drugs (Figure 1) reported in (2). Criteria assessed to evaluate both groups (BAPs and gliptins) included: drug-likeness rules compliance, physicochemical properties, pharmacokinetics, and synthetic accessibility. Furthermore, gastrointestinalabsorbable BAPs lead-likeness and target prediction were calculated as well. 


\section{Data collection}

Molecular descriptors and pharmacokinetic parameters prediction were performed through the following bioinformatic tools: ChemDes (22) and ADMETlab (12) from the Computational Biology \& Drug Design group in China, SwissADME (23), and SwissTargetPrediction (24) from the Swiss Institute of Bioinformatics. In addition, Simplified Molecular Input Line Entry System (SMILES) codes, required for all previously mentioned platforms, were retrieved from DrugBank (25) in the case of gliptins and from BIOPEP-UWM (26) in the case of BAPs.

\section{Drug-likeness and physicochemical evaluation}

Nine different drug-likeness rules were assessed: Lipinski's rule of 5 (27), Veber's filter (28), Ghose filter (29), CMC-50 rules (30), MDDR-like rules (31), BBB rules (32), Egan (Pharmacia) filter (33), Muegge (Bayer) filter (34) and Varma's rules (35). The compliance with every individual set of rules was expressed and analyzed as a percentage value for each forty-eight molecules, obtaining mean percentage values of compliance for both groups and enabling a quantitative comparison between BAPs and gliptins drug-likeness.

On the SwissADME platform (23), five parameters were assessed for physicochemical evaluation: [1] Polarity: topological-polar surface area (TPSA), [2] Flexibility: number of rotatable bonds (No. RB), [3] Size: molecular weight (MW), [4] Lipophilicity: octanol-water coefficient (logP), and [5] Solubility: intrinsic solubility (logS). Given the high variability of $\log P$ values, the data reported from consensus $\log P$ (mean value of $\log P$ calculated by five programs (23)) was taken as the absolute result. Likewise, logS values were taken exclusively from the calculation of the SILICOS-IT program (23). Mean values for each property were calculated, and statistical analysis was performed to determine an existing difference between both groups.

\section{Pharmacokinetic profiling}

Gastrointestinal absorption (Gl-absorption) and P-glycoprotein substrate likeliness were assessed on the SwissADME (23) and ADMETlab (12) platforms. The prediction of these parameters was made based on SMILES inputs. For both groups, SwissADME filtered a set of molecules classified as potential P-glycoprotein substrates and Gl-absorbable. Moreover, analysis carried out on ADMETlab reported a different fraction of molecules as GIabsorbable. Therefore, for this study, only those molecules classified as Gl-absorbable in both platforms were considered as likely absorbable compounds. The resulting molecules were registered and plotted on a BOILED-Egg graph (36). Later on, distribution, metabolism, and excretion parameters were evaluated for likely Gl-absorbable BAPs and gliptins.

The volume of distribution calculation was performed in the ADMETlab platform (12). Blood-Brain Barrier (BBB) diffusion was assessed, and bioavailability prediction was estimated with a cut-off point of $\geq 30 \%$ (37) assumed for both gliptins and BAPs. The fraction of Gl-absorbable compounds with a bioavailability $\geq 30 \%$ was analyzed as a comparison criterion between both groups (37).

The metabolism parameters calculation was based on the predicted interactions of DPP-IV inhibiting compounds with CYP450 enzymes. The studied CYP450 enzymes, described on the ADMETlab platform, were the following: CYP1A2, CYP2C19, CYP2C9, CYP2D6, and CYP3A4. Inhibitory properties and substrate likeliness were assessed for both groups. Similarly, excretion was predicted by clearance and half-life estimated values calculated from ADMETlab. Finally, excretion results were compared as mean values for each group.

Synthetic Accessibility score values were retrieved from the SwissADME platform (23) and analyzed to compare in vitro synthetic ease between gliptins and BAPs. Furthermore, probable protein targets were determined for Gl-absorbable BAPs via the SwissTargetPrediction platform (24). The outcomes were presented as binding probabilities obtained for DPP-IV binding and the three most likely binding proteins.

\section{Statistical Analysis}

Results were reported as mean values \pm Standard Error of the Mean (SEM). Statistical analysis was carried out using a one-way ANOVA test with a significance level of 0.05 .

\section{RESULTS AND DISCUSSION}

\section{Drug-likeness compliance}

Drug-like parameters are widely used to evaluate compounds as suitable drug candidates based on molecular/structural descriptors and quantitative prediction models assessed by machine learning methodologies (38). Hence, drug-likeness rules have been established, allowing the design of in 
silico compound-screening processes that enable drug candidates' identification based on criteria particularly stated by each set of rules (39).

The results obtained in this study showed that neither gliptins nor BAPs displayed a $100 \%$ compliance with the nine drug-likeness guidelines assessed, mainly due to the particular threshold values stated for each rule (40). For visual purposes, drug-likeness evaluation results are presented in a colormap (Figure 2). All thirty-six peptides exhibited high variability of compliance within the different rules assessed, showing the highest percentage (fewer violations) for Lipinski's rule of 5 and the lowest percentage (more violations) for BBB rule, with no peptide scoring $>75 \%$. Furthermore, in silico evaluation revealed that parameters assessed by drug-likeness rules such as molecular weight, the number of atoms, the number of hydrogen bond donors and acceptors, molar refractivity, and the number of rigid and rotatable bonds were exceeded by oligopeptides ( $>3$ aa residues). Consequently, pentapeptides (ID 7 and ID 9) reported lesser compliance when compared to dipeptides, which showed values within acceptable ranges and, as stated by Lipinski et al. (30), could display better drug-like properties due to the absence of rules violations.

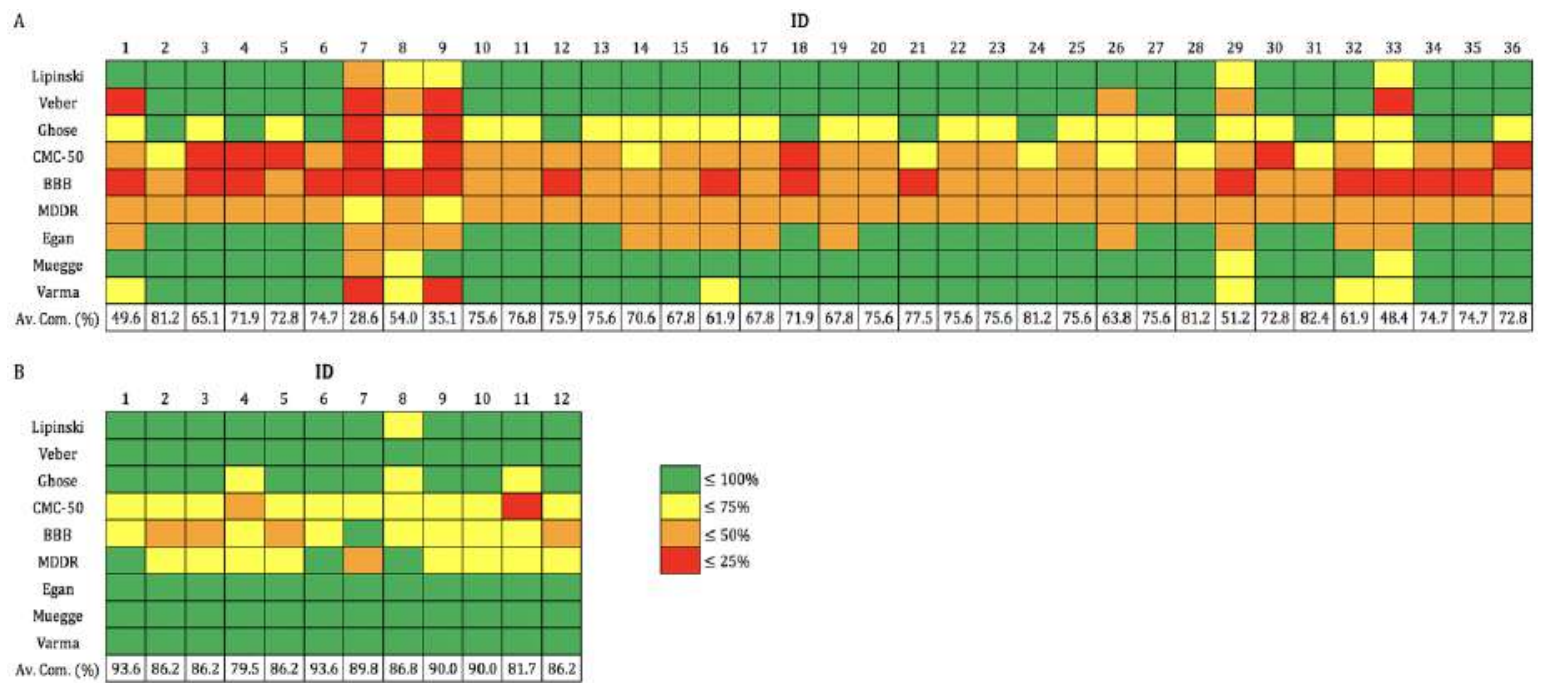

Figure 2. Colormap of compliance with drug-likeness rules. (A) indicates BAPs results; (B) indicates gliptins results. Color conventions: green, $\leq 100 \%$; yellow, $\leq 75 \%$; orange, $\leq 50 \%$, red, $\leq 25 \%$. Av. Com. (\%): Average compliance percentage.

As expected for approved drugs, gliptins exhibited considerably high compliance values. Lipinski's, Veber's, and Varma's rules compliance revealed no significant difference $(p>0.05)$ between BAPs and gliptins, yet for the sparing six guidelines, a significant difference $(p<0.05)$ was reported. Mean values of compliance are presented in Table 2.

Table 2. Mean values of compliance with assessed drug-likeness rules.

\begin{tabular}{lcc}
\hline \multirow{2}{*}{ Drug-likeness Rule } & \multicolumn{3}{c}{ Mean Compliance \pm SEM } \\
\cline { 2 - 3 } & BAPs (\%) & Gliptins (\%) \\
\hline Lipinski $^{*}$ & 96.001 .84 & 97.901 .99 \\
Veber $^{*}$ & 84.705 .94 & 100.000 .00 \\
Ghose & 79.902 .92 & 93.803 .13 \\
CMC-50 & 48.603 .53 & 66.705 .38 \\
BBB & 18.502 .76 & 58.905 .81 \\
MDDR & 35.201 .31 & 72.905 .26 \\
Egan & 81.904 .00 & 100.000 .00 \\
Muegge $^{*}$ & 85.601 .71 & 99.100 .89 \\
Varma $^{*}$ & 86.103 .67 & 98.301 .60 \\
\hline
\end{tabular}

*( $p>0.05)$ no significant difference. SEM, standard error of the mean; BAPs, Bioactive peptides. 
For both gliptins and BAPs, the BBB rule was the highest violated. Nonetheless, it should be noted that $\mathrm{BBB}$ rule assessed properties are those aiming to estimate blood-brain barrier diffusion (41), for which no DPP-IV inhibiting compound showed inclination. Lower lipophilicity, molar refractivity, number of rings, and number of rigid bonds in BAPs are attributed to the low compliance with CMC-50 and MDDR rules. In addition, BBB, MDDR, and CMC-50 were the lowest-scored guidelines for both groups, with a mean compliance percentage $<49 \%$ for BAPs and $<67 \%$ for gliptins.

While we aimed to determine the similarity of drug-likeness rules compliance between formerly approved drugs (gliptins) and BAPs to evaluate their potential as drug candidates, only three druglikeness rules showed no difference between gliptins and BAPs. Still, BAPs exhibited a mean compliance percentage higher than $79 \%$ with six of the assessed drug-likeness rules (Table 2). Therefore, mean compliance percentages (>79\%) enable milk-derived BAPs classification as suitable drug-like compounds according to Lipinski, Veber, Ghose, Egan, Muegge, and Varma guidelines. As a result, the compliance above suggests that these BAPs should exhibit optimal pharmacokinetic properties $(21,22)$.

At last, to address the validity of the results obtained, we performed the formerly mentioned analysis on a random dataset of twelve BAPs (same sample length as gliptins). The average compliance values kept the same proportions as shown in Table 2; however, no significant difference was found in four out of nine drug-likeness rules. Given data variability, further analysis of drug-likeness was performed exclusively for the BAPs classified as gastrointestinal-absorbable (Gl-absorbable). The results from this analysis are discussed later.

\section{Physicochemical traits}

In silico physicochemical evaluation assessed five parameters for which the resulting mean values are presented in Table 3. When comparing gliptins and milk-derived BAPs, statistical analysis revealed a significant difference $(p<0.05)$ for all analyzed parameters - polarity (TPSA), flexibility (No. RB), size (MW), lipophilicity ( $\log P)$, and solubility (logS). Results revealed that gliptins exhibited higher lipophilicity and bigger size, while milk-derived BAPs revealed higher solubility, flexibility, and polarity.

Similar to the drug-likeness analysis, the physicochemical evaluation was performed with a random dataset of twelve BAPs. In this case, the statistical significance reported when comparing both groups was the same as the one shown in Table 3. Still, physicochemical properties were assessed further in this study for gastrointestinal-absorbable BAPs and gliptins.

Table 3. Mean values of calculated physicochemical parameters.

\begin{tabular}{|c|c|c|}
\hline \multirow{2}{*}{ Parameter } & \multicolumn{2}{|c|}{ Mean Compliance \pm SEM } \\
\hline & BAP & Gliptins \\
\hline TPSA $\left(\AA^{2}\right)$ & 122.965 .08 & $91.05 \quad 4.28$ \\
\hline No. RB & 8.500 .47 & 4.830 .54 \\
\hline $\mathrm{MW}\left(\mathrm{g} \cdot \mathrm{mol}^{-1}\right)$ & 273.1013 .88 & 388.4215 .76 \\
\hline $\log S\left(\log \mathrm{mol} \cdot \mathrm{dm}^{-3}\right)$ & $-1.46 \quad 0.20$ & -3.750 .32 \\
\hline $\log P$ & 0.060 .16 & 1.600 .31 \\
\hline
\end{tabular}

SEM, standard error of the mean; BAP, bioactive peptide; TPSA, topological-polar surface area; No. RB, number of rotable bonds; MW, molecular weight.

When analyzing the physicochemical traits, results revealed that BAPs hold considerable advantages over gliptins. Greater polarity, assessed by the TPSA values, could be attributed to their amphoteric properties, many acidic groups, and hydrogenbond formation capacity. Evaluating this parameter is of significant importance as polarity increases hydrophilicity and hydrogen-bond interactions, which have been reported to contribute to solubility and peptide-induced enzymatic inhibition (43). As a parameter tightly linked to polarity, solubility is certainly one of the most important properties to assess in drug-like compounds. Values obtained from the logS descriptor help predict solubility, designating a molecule as soluble with result $>-4 \log \mathrm{mol} \cdot \mathrm{dm}^{-3}$ (44). As for this study, both gliptins and BAPs were above this threshold. The aforementioned physicochemical parameters are crucial for drugs' pharmacokinetics; for instance, gastrointestinal absorption requires drugs to be in a solution for them to be absorbed; thus, higher solubility represents suitable gastrointestinal uptake and increased bioavailability (45).

Compounds' flexibility is assessed by the number of rotatable bonds. The greater flexibility found for BAPs might be explained due to the low number of rings in their structures. High flexibility values influence drug-like compounds' bioavailability (46). Still, recent studies suggest that due to conformational changes in the target protein, ligand flexibility enhances pharmacokinetics and the pharmacodynamic properties of a drug (46).

On the other hand, lipophilicity prediction reported values lower than 3 for both BAPs and gliptins. These 
results suggest that these compounds have poor cell membrane permeability and are, on the contrary, mainly retained in the bloodstream (47). Furthermore, due to DPP-IV blood plasma confinement, lipid bilayer permeability is not expected for DPP-IV inhibiting compounds as much as hydrophilicity is (48). Regarding size, gliptins exhibit higher molecular weight, which results from heteroatoms such as sulfur and fluorine. Molecular weight is tightly correlated with synthetic accessibility; thus, a smaller size is crucial for drug-like compounds (49). Consequently, size values observed in milk-derived BAPs suggest a less complex synthesis when compared to gliptins.

\section{Gastrointestinal absorption}

Two main outcomes were evidenced when assessing gastrointestinal absorption (Gl absorption) and blood-brain barrier (BBB) diffusion. None of the DPP-IV inhibiting compounds reported to be BBBpermeable, and only a small fraction of BAPs are likely
Gl-absorbable compounds based on the prediction of SwissADME and ADMETlab. Furthermore, P-glycoprotein substrate likeliness was assessed. Out of thirty-six milk-derived BAPs, only nine dipeptides (ID 3, 4, 6, 12, 18, 20, 30, 31, 35) were classified as Gl-absorbable. On the other hand, the totality of gliptins exhibited a high estimated probability of Gl absorption. Regarding P-glycoprotein substrate characteristics, eight BAPs, from which only three were classified as Gl-absorbable (ID 18, 20, 31), reported being suitable substrates; whereas, for gliptins, nine out of twelve exhibited P-glycoprotein substrate characteristics. Schematic representation of absorbable compounds is shown in Figure 3. BOILED-Egg graph displays filtered molecules within different colored areas: white area represents likely Gl absorption; yellow represents possible BBB diffusion. Red-colored molecules are nonsuitable P-glycoprotein substrates, and blue-colored molecules are feasible substrates.
A

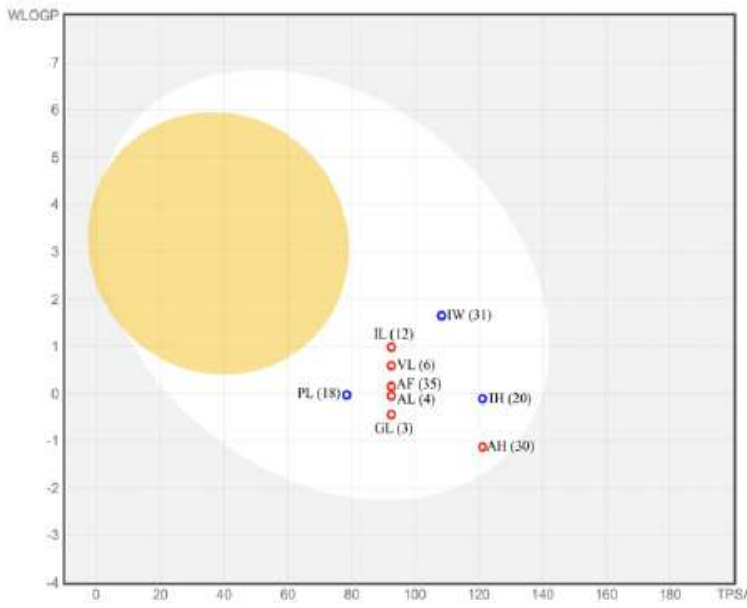

B

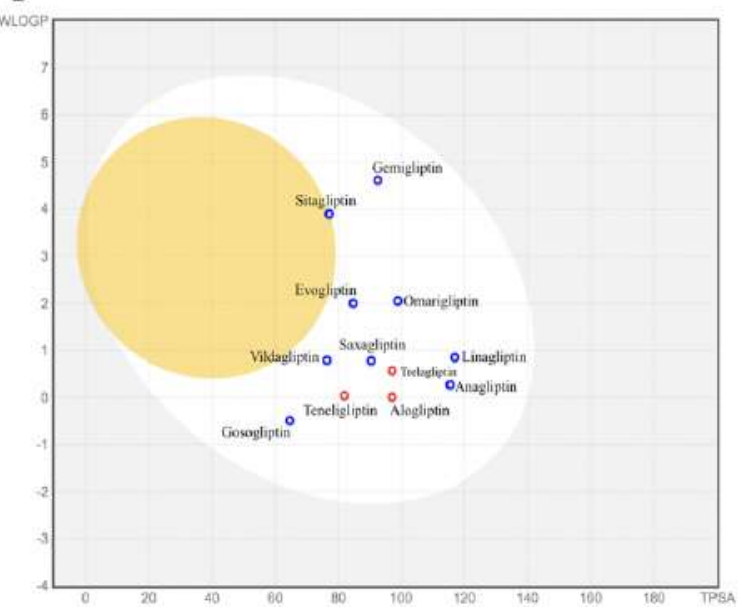

Figure 3. BOILED-Egg graph. (A) indicates BAPs results; (B) indicates gliptins results. Red-colored compounds represent non-suitable P-glycoprotein substrates; Blue-colored compounds represent P-glycoprotein substrates. White area: Gl-absorbable; Yellow area: BBB likely diffusion. TPSA, topological polar surface area; BAP, bioactive peptide.

Figure $3(\mathrm{~A})$ displays the ID and sequence of all Gl-absorbable BAPs. Based on these findings, we observed that $\mathrm{Gl}$-absorbable BAPs seem to be a small fraction of the whole number of BAPs released from milk proteins' digestion. Nonetheless, these Gl-absorbable BAPs appear to fulfill drug-likeness guidelines much better than non-absorbable BAPs as they showed no statistically significant difference of compliance with gliptins ( $p>0.05$ ) for five out of nine assessed rules. Likewise, these Gl-absorbable peptides exhibited no significant difference with gliptins $(p>0.05)$ in terms of polarity, yet similar proportions as the ones shown in Table 2 were kept; greater polarity, flexibility and solubility for Gl-absorbable BAPs, and greater lipophilicity and size for gliptins.

Nine out of twelve gliptins were classified as feasible P-glycoprotein substrates, while only three Gl-absorbable BAPs reported substrate likeliness. Assessing this parameter remains crucial in drug candidates evaluation as P-glycoprotein substrates are likely to be extruded from enterocytes (50). Hence, a lower probability of being a P-glycoprotein 
substrate for BAPs implies a considerable advantage over gliptins in $\mathrm{Gl}$ absorption.

\section{Distribution \& Bioavailability}

The volume of distribution (VD) prediction reported a mean value of $-0.62 \pm 0.23$ for milk-derived BAPs and $-0.30 \pm 0.07$ for gliptins. Statistical analysis revealed no significant differences $(p>0.05)$. While $V D$ values $<0.07$ indicate that compounds are highly hydrophilic and blood-confined, gliptins and BAPs

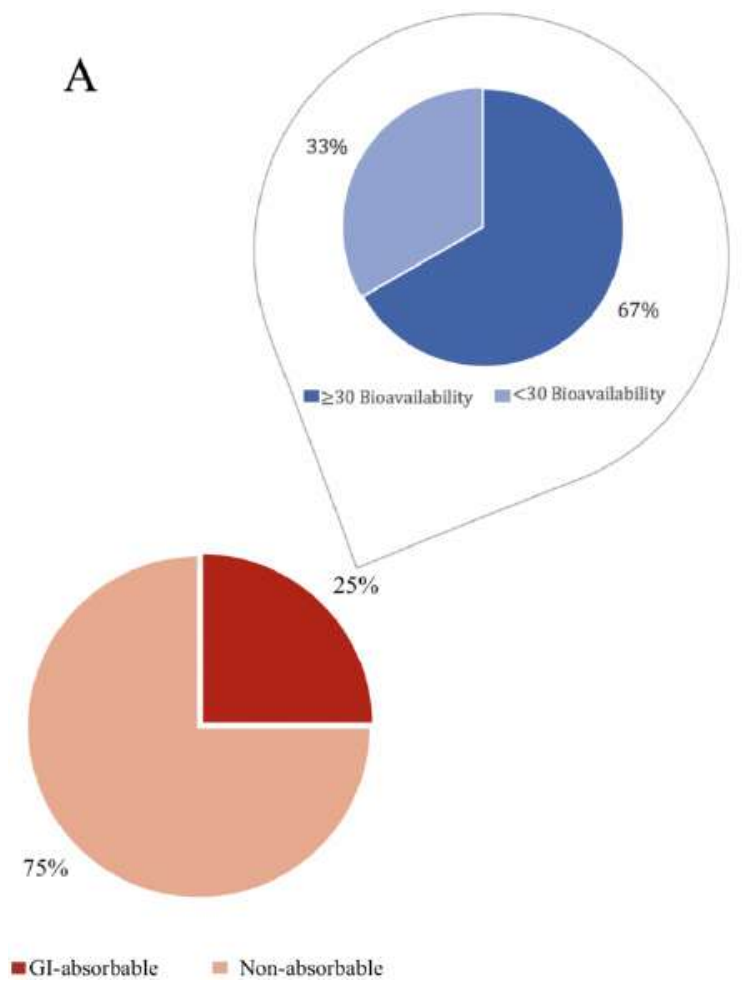

mean values were not within the optimal range for drugs: $0.04-20.00$ (51). Still, it must be mentioned that five gliptins reported VD values $>0.04$ (Table 4). Bloodstream confinement is advantageous for DPPIV inhibitors as incretin hormones degradation occurs in blood plasma (52), suggesting that the obtained results might be favorable despite not reaching the optimal range. Further on, bioavailability was evaluated for Gl-absorbable BAPs, and results are presented in Figure 4.

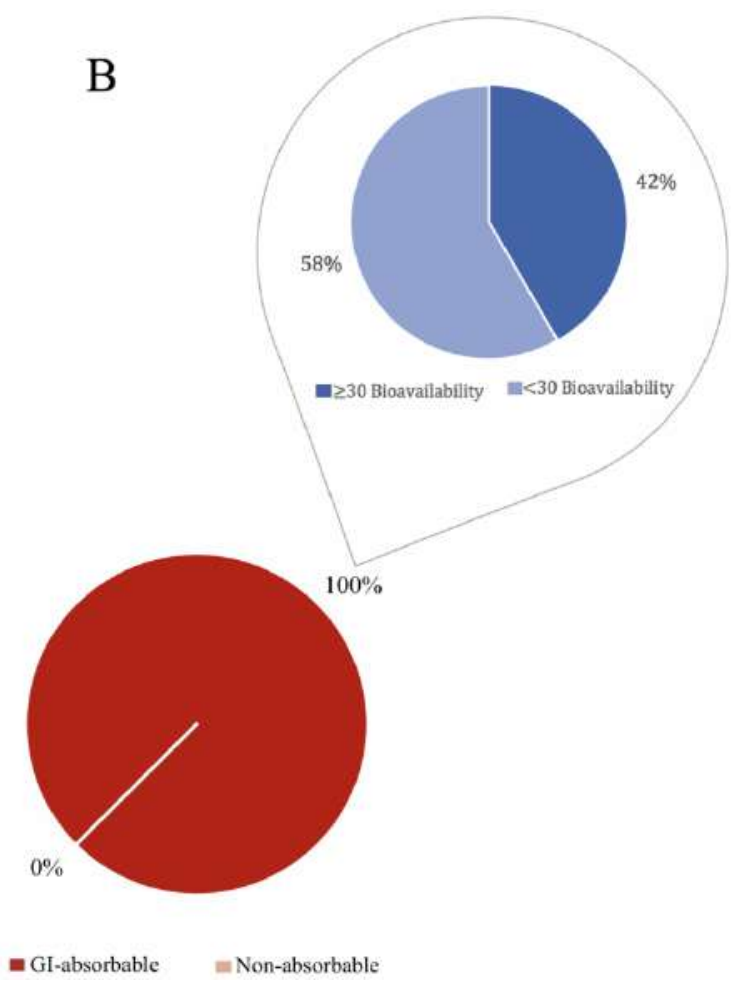

Figure 4. Bioavailability of gastrointestinal-absorbable compounds. (A) Results for Bioactive peptides; (B) Results for gliptins. GIabsorbable percentage represents the fraction of molecules reported as likely absorbed both in SwissADME and ADMETlab.

Bioavailability prediction was assessed with a cut-off point of $30 \%$ (37). As mentioned before, only nine (25\%) of the thirty-six BAPs were classified as highly Gl-absorbable; however, out of these Gl-absorbable compounds, $67 \%$ (six) and 33\% (three) exhibited a bioavailability $\geq 30 \%$ and $<30 \%$, respectively (Figure 4). As of gliptins, in which $100 \%$ of them were classified as Gl-absorbable, only $42 \%$ (five) reported $\geq 30 \%$ bioavailability, whereas the sparing $58 \%$ (seven) showed a predicted value $<30 \%$. Though in silico assessment has shown a promising accuracy of $76 \%$ (53), in vivo assessment remains indispensable to conclude bioavailability values accurately.

\section{Metabolism \& Excretion}

Cytochromes P450 (CYP450) are tightly involved in xenobiotics metabolism; thus, addressing drug-like compounds' interactions with CYP450 enzymes is of great relevance for drug candidates screening (54). The results from the evaluation of the CYP450 interactions are presented in Table 4. As shown, BAPs were revealed to be unlikely substrates/ inhibitors to the majority of CYP450, yet only one peptide (ID 30) exhibited suitable properties for CYP2C9 inhibition. On the other hand, one peptide (ID 31) showed to be a viable substrate for CYP2D6, which is involved in the metabolic 
pathway of small amine-containing molecules and might explain the affinity for lle-Trp dipeptide (ID 31) (55). Gliptins, on the contrary, reported a higher number of interactions with CYP450 enzymes compared to BAPs. Feasible inhibitory interactions were predicted for four gliptins (ID 4, 7, 8, 11), and regarding metabolism, eight of them (ID 1, 2-4, 9-12) were classified as likely CYP450 substrates for at least one cytochrome enzyme (Table 4).

Excretion was assessed by clearance and half-life prediction. In concordance with their aminoacidic properties, Gl-absorbable BAPs showed a slightly lower clearance value ( $p>0.05)$ than gliptins, but still, their half-life was significantly lower $(p<0.05)$. While BAPs clearance values represented prolonged serum concentrations due to a lower excretion rate, their lower half-life suggested that if ever administered, they could require an increased dosing regimen and a higher consumption frequency to achieve an effective, if any, therapeutic effect (56). At last, pharmacokinetic parameters assessed for Gl-absorbable BAPs and gliptins are presented in Table 4.

Table 4. Pharmacokinetic predicted values for all Gl-absorbable DPP-IV inhibitors.

\begin{tabular}{|c|c|c|c|c|c|c|}
\hline $\begin{array}{c}\text { DPP-IV } \\
\text { inhibitor }\end{array}$ & ID & VD & Bioavailability & Clearance* $^{*}$ & $\mathbf{T}_{1 / 2}(\mathrm{~h})$ & CYP450 interactions \\
\hline \multirow{9}{*}{ BAP } & 3 & -0.56 & $\geq 30 \%$ & 1.02 & 1.28 & - \\
\hline & 4 & -1.23 & $\geq 30 \%$ & 1.15 & 1.24 & - \\
\hline & 6 & -0.48 & $\geq 30 \%$ & 1.33 & 1.36 & - \\
\hline & 12 & -0.48 & $<30 \%$ & 1.35 & 1.27 & - \\
\hline & 18 & -0.49 & $<30 \%$ & 1.42 & 0.88 & - \\
\hline & 20 & -0.55 & $\geq 30 \%$ & 1.50 & 0.61 & - \\
\hline & 30 & -0.63 & $\geq 30 \%$ & 1.40 & 0.7 & CYP2D6 ${ }^{a}$ \\
\hline & 31 & -0.59 & $<30 \%$ & 1.74 & 1.01 & CYP2D6 $^{\mathrm{b}}$ \\
\hline & 35 & -0.62 & $\geq 30 \%$ & 1.48 & 0.69 & - \\
\hline \multirow{14}{*}{ Gliptins } & 1 & -0.72 & $\geq 30 \%$ & 1.25 & 1.22 & CYP3A4 ${ }^{\mathrm{b}}$ \\
\hline & 2 & 0.16 & $\geq 30 \%$ & 1.87 & 1.41 & - \\
\hline & 3 & -2.72 & $<30 \%$ & 2.06 & 1.32 & CYP3A4 ${ }^{b}$ \\
\hline & \multirow{2}{*}{4} & \multirow{2}{*}{0.12} & \multirow{2}{*}{$<30 \%$} & \multirow{2}{*}{1.57} & \multirow{2}{*}{1.90} & CYP2C9 /CYP3A4 $4^{\mathrm{ab}}$ \\
\hline & & & & & & CYP1A2 $2^{b} / C Y P 2 C 19^{b}$ \\
\hline & \multirow{2}{*}{5} & \multirow{2}{*}{0.23} & \multirow{2}{*}{$<30 \%$} & \multirow{2}{*}{1.84} & \multirow{2}{*}{1.47} & CYP2D96 $/$ CYP3A4 ${ }^{\mathrm{b}}$ \\
\hline & & & & & & CYP1A2 $2^{b} / C Y P 2 C 19^{b}$ \\
\hline & 6 & -0.08 & $\geq 30 \%$ & 1.76 & 1.30 & - \\
\hline & 7 & -0.38 & $<30 \%$ & 1.60 & 1.65 & CYP2C9a \\
\hline & 8 & -0.63 & $<30 \%$ & 1.00 & 1.35 & CYP2C19a \\
\hline & 9 & -0.02 & $<30 \%$ & 1.46 & 1.36 & CYP1A2 $/$ CYP2D $6^{b} / C Y P 3 A 4^{b}$ \\
\hline & 10 & -0.19 & $\geq 30 \%$ & 1.18 & 1.74 & CYP1A2 $/$ CYP3A $4^{\mathrm{b}}$ \\
\hline & 11 & 0.49 & $<30 \%$ & 1.57 & 1.72 & CYP1A2b/CYP3A4b/CYP2D6 \\
\hline & 12 & 0.17 & $\geq 30 \%$ & 1.85 & 1.38 & CYP1A2b/CYP2D $6^{\mathrm{b}} / \mathrm{CYP} 3 \mathrm{~A} 4^{\mathrm{b}}$ \\
\hline
\end{tabular}

VD, Volume of Distribution; T/12, half-life; BAP, Bioactive Peptide. ${ }^{*}\left(\mathrm{~cm}^{3} \cdot \mathrm{min}^{-1} \cdot \mathrm{kg}^{-1}\right)$. ${ }^{\text {alnhibitor. }}{ }^{\mathrm{b}}$ Substrate.

\section{Lead-likeness}

Lead-like properties are based on lipophilicity and molecular weight; both assessed to improve the chances of lead-like molecules being suitable candidates for drug design (57). The lead-likeness evaluation was based on size (MW), lipophilicity $(\log P)$, and flexibility (No. RB) as stated by (58) and was exclusively carried out for $\mathrm{Gl}$-absorbable BAPs. In addition, an estimated synthetic accessibility score was calculated for Gl-absorbable BAPs based on molecular structure complexity (59). According to 
our findings, BAPs exhibit suitable lipophilicity but lack the appropriate molecular weight; hence, leadlikeness showed to be mainly limited by their size. In addition, only one peptide (ID-12) exhibited several rotatable bonds $>7$, leading to a second violation. As a result, eight out of nine Gl-absorbable BAPs showed a $66.67 \%$ compliance with lead-likeness rules, whereas only one (ID-12) showed a $33.33 \%$ compliance.

In regards to synthetic accessibility score, GIabsorbable BAPs reported promising results when compared to gliptins. The mean synthetic accessibility score for gliptins was $4.05 \pm 0.15$, while BAPs reported a mean value of $2.69 \pm 0.14$ Scores range from 1-10, where 1 was attributed to easily synthesizable structures, and 10 to hard synthesizable compounds (60). Outcomes derived from synthetic accessibility prediction showed a significant difference $(p<0.05)$, suggesting that $\mathrm{Gl}$ absorbable BAPs are more easily synthesized when compared to gliptins.

\section{Target Prediction}

Biologically active peptides are known to exhibit target-ligand affinity for more than one single protein (11). Therefore, the nine Gl-absorbable BAPs were subjected to binding probability assays carried out by estimating their affinity for proteases and DPP-IV. Results of the initial evaluation are shown in Figure 5, displaying the proteaseinhibiting probability and the DPP-IV inhibiting probability.

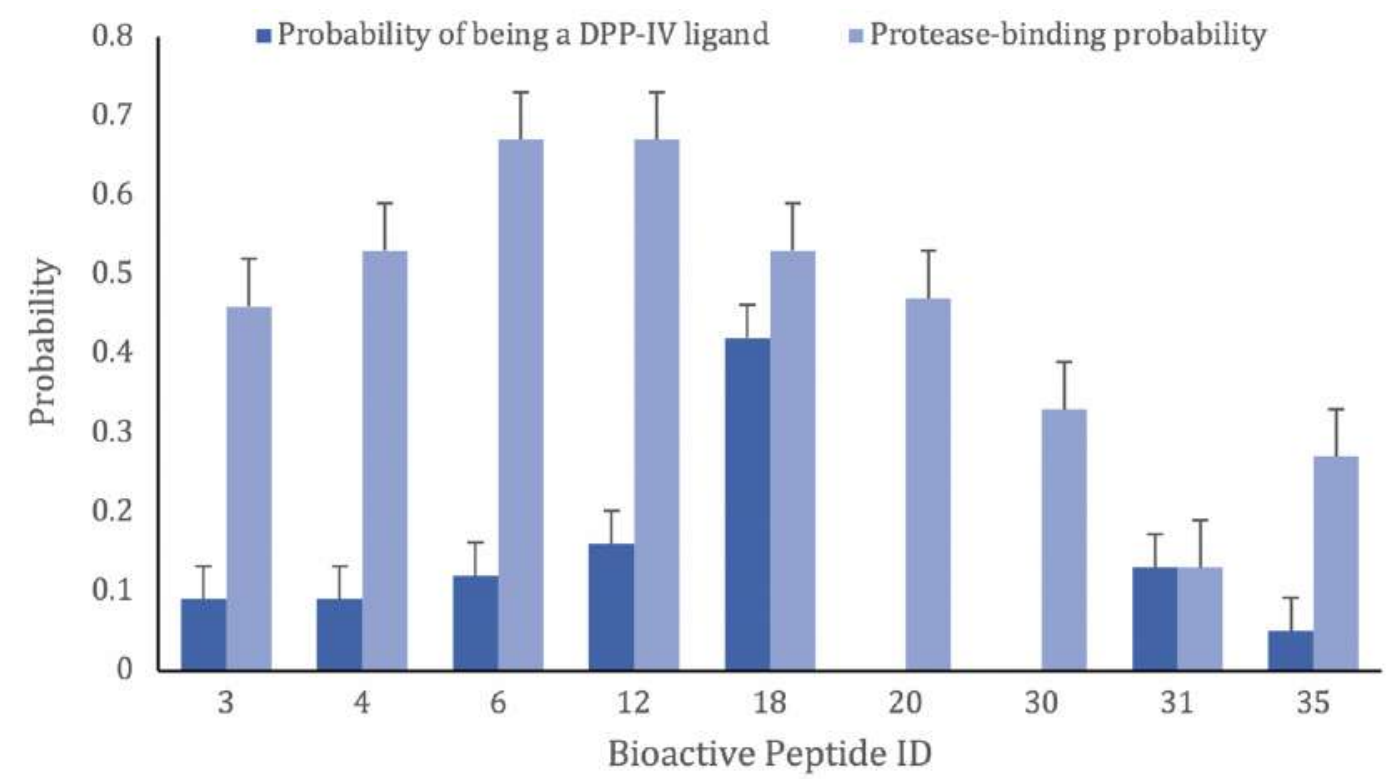

Figure 5. Protease and DPP-IV binding probability \pm SE. SE; standard error.

Predicted probability values showed high chances of protease binding, ranging from $0.13-0.67$. Alternatively, DPP-IV binding prediction presented values within a $0.00-0.42$ probability range. The highest DPP-IV inhibiting probability was achieved by PL dipeptide (ID 18), which exhibited a high protease-binding (0.53) and DPP-IV-binding (0.42) probability. Unexpectedly, a result of 0.00 binding probability was obtained for two peptides (ID 20 and ID 30); however, in vitro studies had found a DPP-IV inhibition ratio of $6.50 \pm 0.06$ for $\mathrm{IH}$ dipeptide (ID 20) and a $27.9 \pm 02.40$ DPP-IV inhibition ratio for $\mathrm{AH}$ dipeptide (ID 30) (17). Remarkable results were derived from this analysis; for instance, the most likely protease-binding BAPs were (ID 6) and (ID 12), both with a C-terminal leucine residue and an $\mathrm{N}$-terminal neutral amino acid. Similarly, the lowest scored peptide (ID 31) was the only Gl-absorbable dipeptide with a tryptophan residue. Complementary findings suggest that food-derived BAPs have potential binding interactions with a particular affinity for a broad range of proteolytic enzymes (61) relative frequency of release of fragments with a given activity by selected enzymes. Furthermore, an evaluation of the suitable binding target proteins was carried out for each Gl-absorbable peptide, resulting in eleven proteins classified as achievable targets for Gl-absorbable BAPs (Table 5). 
Table 5. Gl-absorbable BAPs affinity and binding probability.

\begin{tabular}{cccc}
\hline Sequence (ID) & Protein 1 & Protein 2 & Protein 3 \\
\hline GL (3) & COX-2 (0.18) & HLA-A3 (0.10) & DPP-IV (0.09) \\
AL (4) & COX-2 (0.21) & DPP-IV (0.09) & HLA-A3 (0.08) \\
VL (6) & Calpain-I (0.25) & ACE (0.15) & COX-2 (0.13) \\
IL (12) & ACE (0.27) & Calpain-I (0.27) & DPP-IV (0.16) \\
PL (18) & DPP-IV (0.42) & ACE (0.28) & Calpain-I (0.19) \\
IH (20) & CPB-2 (0.18) & Ang-II R (0.13) & CPB (0.13) \\
AH (30) & CPB-2 (0.21) & Ang-II R (0.07) & CPB (0.07) \\
IW (31) & ACE (1.00) & ET-A Receptor (0.21) & H-Opioid Receptor (0.20) \\
AF (35) & Calpain-I (0.30) & Neprilysin (0.16) & SMOT (0.16) \\
\hline
\end{tabular}

COX-2, Cyclooxygenase-2; HLA-A3, Human Leukocyte Antigen-A3; DPP-IV, Dipeptidil-Peptidase IV; ACE, Angiotensin Converting Enzyme; CPB, Carboxypeptidase B; CPB-2, Carboxypeptidase B-2; Ang-II R, Ang-II Receptor; ET-A, Endothelin Receptor ET-A; SMOT, Small Intestine Oligopeptide Transporter. (Value): Binding Probability.

As presented in Table 5, cyclooxygenase-2 (COX-2) was reported as a viable target for three peptides (ID 3, 4, 6) with a binding probability within a range of $0.13-0.21$. These results suggest that BAPs hold potential anti-inflammatory properties. Angiotensinconverting enzyme (ACE) was reported as a target for four BAPs, with one peptide (ID-31) scoring a $100 \%$ binding probability. In addition to $A C E$, BAPs reported an affinity for endothelin receptor-A (ET-A Receptor), angiotensin-II receptor (Ang-II R), and Neprilysin. In consequence, a systemic blood pressure regulatory effect could also be exerted by BAPs.

Of particular importance to this study, four peptides (ID 6, 12, 18, 35) reported a binding probability within a range of 0.19-0.30 for Calpain-I. This enzyme has shown to be involved in DM vascular disease (62); hence Calpain-I modulators have been highlighted as suitable drug candidates for T2DM therapy $(63,64)$. Results derived from this investigation revealed that BAPs affinity for Calpain-I conveyed T2DM health-promoting properties aside from the inhibition of incretin hormones degradation.

Final results indicate that dipeptide PL (ID 18) is likely the most suitable DPP-IV inhibiting BAP given its drug-likeness compliance, protease, and DPPIV binding probability, Gl-absorption probability, synthetic accessibility and lead-likeness, lack of CYP450 interactions, and high DPP-IV affinity (also, worth mentioning high affinity for Calpain-I). However, pharmacokinetic parameters such as $<30 \%$ bioavailability, clearance, and half-life might limit its therapeutic potency.

Addressing the pharmacokinetic properties of BAPs requires the study of wasteful experimental designs; hence, in silico experimentation emerges as a promising strategy to accelerate drug filtering by compound screening methods and toxicology and pharmacokinetic studies (65). Nonetheless, in silico prediction of physicochemical and pharmacokinetic parameters is based on a theoretical approach. Given these limitations, we encourage further research studies to assess the in vivo potential of DPP-IV inhibiting BAPs to determine and perhaps identify the currently unknown properties of these nutraceuticals as suitable therapeutical agents for T2DM.

\section{CONCLUSION}

This study developed a first-time reported physiochemical and pharmacokinetic profiling of bioactive peptides derived from milk proteins digestion. Nine biopeptides were classified as gastrointestinal-absorbable. Compared to gliptins, they exhibited no significant difference in five drug-like guidelines compliance, lesser CYP450 interactions, higher synthetic ease. Some reported an important affinity for DPP-IV and Calpain-I. Likewise, physicochemical estimated parameters revealed higher solubility, flexibility, and polarity for nutraceuticals. Thus, obtained results revealed that Gl-absorbable bioactive peptides under study exhibit important properties that establish them as feasible drug-like compounds based on in silico pharmacokinetic profiling and drug-likeness assessment; however, testing their therapeutic potency remains subject to further studies.

\section{CONFLICT OF INTEREST}

The authors report no conflict of interest. 


\section{ACKNOWLEDGMENTS}

The authors thank Gimnasio Vermont (Bogotá, Colombia) for their support in this study and associated Professor Nancy E. Parrado for drafting and editing assistance.

\section{AUTHORS' CONTRIBUTIONS}

Conceptualization: J. A. Barrero, F. Cabrera; Methodology: C. M. Cruz; Results and Discussion: J. A. Barrero; Review and editing: C. M. Cruz, F. Cabrera. All authors agree upon the final version.

\section{REFERENCES}

1. Cole JB, Florez JC. Genetics of diabetes mellitus and diabetes complications. Nat Rev Nephrol. 2020;16(7):377-90. DOI: https:// doi.org/10.1038/s41581-020-0278-5

2. Rieddle MC, Ahmann AJ. Therapeutics of Type 2 Diabetes Mellitus. In: Williams Textbook of Endocrinology. 14th ed. Elsevier; 2020 p. 1386.

3. Doumas M, Imprialos K, Stavropoulos K, Athyros VG. Pharmacological Management of Type 2 Diabetes Complications. Curr Vasc Pharmacol. 2020;18(2):101-3. DOI: https://doi.org/10.2 174/157016111802200101155519

4. Mockus I, Trujillo M. Obesidad y Enfermedades Asociadas, 1st ed. Ismena M, Martha T, editors. Universidad Nacional de Colombia 2013. $230 \mathrm{p}$.

5. Paschou SA, Siasos G, Bletsa E, Stampouloglou PK, Oikonomou E, Antonopoulos AS, et al. The Effect of DPP-4i on Endothelial Function and Arterial Stiffness in Patients with Type 2 Diabetes: A Systematic Review of Randomized Placebo-controlled Trials. Curr Pharm Des. 2020;26(46):5980-7. DOI: https://doi.org/10.2174/13 81612826666200417153241

6. Sachdeva V, Roy A, Bharadvaja N. Current Prospects of Nutraceuticals: A Review. Curr Pharm Biotechnol. 2020;21(10):88496. DOI: https://doi.org/10.2174/1389201021666200130113441

7. Premi M, Bansal V. Nutraceuticals for Management of Metabolic Disorders. In: Treating endocrine and metabolic disorders with herbal medicines. 2021. p. 298-320.

8. Jao C-L, Hung C-C, Tung Y-S, Lin P-Y, Chen M-C, Hsu K-C. The development of bioactive peptides from dietary proteins as a dipeptidyl peptidase IV inhibitor for the management of type 2 diabetes. BioMedicine. 2015;5(3):14. DOI: https://doi.org/10.7603/ s40681-015-0014-9

9. Patil P, Mandal S, Tomar SK, Anand S. Food protein-derived bioactive peptides in management of type 2 diabetes. Eur J Nutr. 2015;54(6):863-80. DOI: https://doi.org/10.1007/s00394-0150974-2

10. Acquah C, Dzuvor CK, Tosh S, Agyei D. Anti-diabetic effects of bioactive peptides: recent advances and clinical implications. Crit Rev Food Sci Nutr. 2020;1-14. DOI: https://doi.org/10.1080/1040 8398.2020.1851168

11. Iwaniak A, Minkiewicz P, Darewicz M, Hrynkiewicz M. Food proteinoriginating peptides as tastants - Physiological, technological, sensory, and bioinformatic approaches. Food Res Int. 2016;89:2738. DOI: https://doi.org/10.1016/j.foodres.2016.08.010

12. Dong J, Wang N-N, Yao Z-J, Zhang L, Cheng Y, Ouyang D, et al. ADMETlab: a platform for systematic ADMET evaluation based on a comprehensively collected ADMET database. J Cheminformatics. 2018;10(1):29. DOI: https://doi.org/10.1186/ s13321-018-0283-x

13. Barrero JA, Cruz CM, Casallas J, Vásquez JS. Evaluación in silico de péptidos bioactivos derivados de la digestión de proteínas presentes en la leche de bovino (B.taurus), oveja (O.aries), cabra (C.hircus) y búfalo (B.bubalis). TecnoLógicas. 2020;50(24). DOI: https://doi.org/10.22430/22565337.1731

14. Nongonierma AB, Mooney C, Shields DC, FitzGerald RJ. Inhibition of dipeptidyl peptidase IV and xanthine oxidase by amino acids and dipeptides. Food Chem. 2013;141(1):644-53. DOI: https:// doi.org/10.1016/j.foodchem.2013.02.115

15. Nongonierma AB, FitzGerald RJ. An in silico model to predict the potential of dietary proteins as sources of dipeptidyl peptidase IV (DPP-IV) inhibitory peptides. Food Chem. 2014;165:489-98. DOI: https://doi.org/10.1016/j.foodchem.2014.05.090

16. Cheung HS, Wang FL, Ondetti MA, Sabo EF, Cushman DW. Binding of peptide substrates and inhibitors of angiotensin-converting enzyme. Importance of the $\mathrm{COOH}$-terminal dipeptide sequence. J Biol Chem. 1980;255(2):401-7. https://pubmed.ncbi.nlm.nih. gov/6243277/

17. Lan VTT, Ito K, Ohno M, Motoyama T, Ito S, Kawarasaki Y. Analyzing a dipeptide library to identify human dipeptidyl peptidase IV inhibitor. Food Chem. 2015;175:66-73. DOI: https:// doi.org/10.1016/j.foodchem.2014.11.131

18. Nongonierma $A B$, FitzGerald RJ. Susceptibility of milk proteinderived peptides to dipeptidyl peptidase IV (DPP-IV) hydrolysis. Food Chem. 2014;145:845-52. DOI: https://doi.org/10.1016/j. foodchem.2013.08.097

19. Nongonierma AB, FitzGerald RJ. Inhibition of dipeptidyl peptidase IV (DPP-IV) by proline containing casein-derived peptides. J Funct Foods. 2013;5(4):1909-17. DOI: https://doi.org/10.1016/j. jff.2013.09.012

20. Silveira ST, Martínez D, Recio I, Hernández B. Dipeptidyl peptidase-IV inhibitory peptides generated by tryptic hydrolysis of a whey protein concentrate rich in $\beta$-lactoglobulin. Food Chem. 2013;141(2):1072-7. DOI: https://doi.org/10.1016/j. foodchem.2013.03.056

21. Gallego M, Aristoy M-C, Toldrá F. Dipeptidyl peptidase IV inhibitory peptides generated in Spanish dry-cured ham. Meat Sci. 2014;96(2):757-61. DOI: https://doi.org/10.1016/j. meatsci.2013.09.014

22. Dong J, Cao D-S, Miao H-Y, Liu S, Deng B-C, Yun Y-H, et al. ChemDes: an integrated web-based platform for molecular descriptor and fingerprint computation. J Cheminformatics. 2015;7(1):60. DOI: https://doi.org/10.1186/s13321-015-0109-z

23. Daina A, Michielin O, Zoete V. SwissADME: a free web tool to evaluate pharmacokinetics, drug-likeness and medicinal chemistry friendliness of small molecules. Sci Rep. 2017;7(1):42717. DOI: https://doi.org/10.1038/srep42717

24. Daina A, Michielin O, Zoete V. SwissTargetPrediction: updated data and new features for efficient prediction of protein targets of small molecules. Nucleic Acids Res. 2019;47(W1):W357-64. DOI: https://doi.org/10.1093/nar/gkz382

25. Wishart DS, Feunang YD, Guo AC, Lo EJ, Marcu A, Grant JR, et al. DrugBank 5.0: a major update to the DrugBank database for 2018. Nucleic Acids Res. 2018;46(D1):D1074-82. DOI: https://doi. org/10.1093/nar/gkx1037

26. Minkiewicz, Iwaniak, Darewicz. BIOPEP-UWM Database of Bioactive Peptides: Current Opportunities. Int J Mol Sci. 2019;20(23):5978. DOI: https://doi.org/10.3390/ijms20235978

27. Lipinski CA. Drug-like properties and the causes of poor solubility and poor permeability. J Pharmacol Toxicol Methods. 
2000;44(1):235-49. DOI: https://doi.org/10.1016/s1056 $8719(00) 00107-6$

28. Veber DF, Johnson SR, Cheng H-Y, Smith BR, Ward KW, Kopple KD. Molecular Properties That Influence the Oral Bioavailability of Drug Candidates. J Med Chem. 2002;45(12):2615-23. DOI: https://doi.org/10.1021/jm020017n

29. Ghose AK, Viswanadhan VN, Wendoloski JJ. A Knowledge-Based Approach in Designing Combinatorial or Medicinal Chemistry Libraries for Drug Discovery. 1. A Qualitative and Quantitative Characterization of Known Drug Databases. J Comb Chem. 1999;1(1):55-68. DOI: https://doi.org/10.1021/cc9800071

30. Lipinski CA. Lead- and drug-like compounds: the rule-of-five revolution. Drug Discov Today Technol. 2004;1(4):337-41. DOI: https://doi.org/10.1016/j.ddtec.2004.11.007

31. Oprea TI. Property distribution of drug-related chemical databases. J Comput Aided Mol Des. 2000;14(3):251-64. DOI: https://doi.org/10.1023/A:1008130001697

32. Gupta M, Lee HJ, Barden CJ, Weaver DF. The Blood-Brain Barrier (BBB) Score. J Med Chem. 2019;62(21):9824-36. DOI: https://doi org/10.1021/acs.jmedchem.9b01220

33. Egan WJ, Merz, KM, Baldwin JJ. Prediction of Drug Absorption Using Multivariate Statistics. J Med Chem. 2000;43(21):3867-77. DOI: https://doi.org/10.1021/jm000292e

34. Muegge I, Heald SL, Brittelli D. Simple Selection Criteria for Drug-like Chemical Matter. J Med Chem. 2001;44(12):1841-6. DOI: https://doi.org/10.1021/jm015507e

35. Varma MV, Obach RS, Rotter C, Miller HR, Chang G, Steyn SJ, et al. Physicochemical Space for Optimum Oral Bioavailability: Contribution of Human Intestinal Absorption and First-Pass Elimination. J Med Chem. 2010;53(3):1098-108. DOI: https://doi. org/10.1021/jm901371v

36. Daina A, Zoete V. A BOILED-Egg To Predict Gastrointestinal Absorption and Brain Penetration of Small Molecules. ChemMedChem. 2016;11(11):1117-21. DOI: https://doi.org/10.1002/ cmdc. 201600182

37. Tian S, Li Y, Wang J, Zhang J, Hou T. ADME Evaluation in Drug Discovery. 9. Prediction of Oral Bioavailability in Humans Based on Molecular Properties and Structural Fingerprints. Mol Pharm. 2011;8(3):841-51. DOI: https://doi.org/10.1021/mp100444g

38. Tian S, Wang J, Li Y, Li D, Xu L, Hou T. The application of in silico drug-likeness predictions in pharmaceutical research. Adv Drug Deliv Rev. 2015;86:2-10. DOI: https://doi.org/ 10.1016/j. addr.2015.01.009

39. Ou-Yang S, Lu J, Kong X, Liang Z, Luo C, Jiang H. Computational drug discovery. Acta Pharmacol Sin. 2012;33(9):1131-40. DOI: https://doi.org/10.1038/aps.2012.109

40. Loureiro DRP, Soares JX, Costa JC, Magalhães ÁF, Azevedo CMG, Pinto MMM, et al. Structures, Activities and Drug-Likeness of Anti-Infective Xanthone Derivatives Isolated from the Marine Environment: A Review. Molecules. 2019;24(2):243. DOI: https:// doi.org/10.3390/molecules24020243

41. Hitchcock SA. Blood-brain barrier permeability considerations for CNS-targeted compound library design. Curr Opin Chem Biol. 2008;12(3):318-23. DOI: https://doi.org/10.1016/j. cbpa.2008.03.019

42. Jia C-Y, Li J-Y, Hao G-F, Yang G-F. A drug-likeness toolbox facilitates ADMET study in drug discovery. Drug Discov Today. 2020;25(1):248-58. DOI: https://doi.org/10.1016/j. drudis.2019.10.014

43. J Ji D, Xu M, Udenigwe CC, Agyei D. Physicochemical characterisation, molecular docking, and drug-likeness evaluation of hypotensive peptides encrypted in flaxseed proteome. Curr
Res Food Sci. 2020;3:41-50. DOI: https://doi.org/10.1016/j. crfs.2020.03.001

44. Meanwell NA. Improving Drug Candidates by Design: A Focus on Physicochemical Properties As a Means of Improving Compound Disposition and Safety. Chem Res Toxicol. 2011 Sep 19;24(9):1420 56. DOI: https://doi.org/10.1021/t×200211v

45. Das T, Mehta CH, Nayak UY. Multiple approaches for achieving drug solubility: an in silico perspective. Drug Discov Today. 2020;25(7):1206-12. DOl: https://doi.org/10.1016/j. drudis.2020.04.016

46. Caron G, Digiesi V, Solaro S, Ermondi G. Flexibility in early drug discovery: focus on the beyond-Rule-of-5 chemical space. Drug Discov Today. 2020;25(4):621-7. DOI: https://doi.org/10.1016/j. drudis.2020.01.012

47. Testa B, van de Waterbeemd H, Folkers G, Guy R. Pharmacokinetic Optimization in Drug Research: Biological, Physicochemical, and Computational Strategies [Internet]. 1st ed. Wiley; 2001 [cited 2021 May 22]. Available from: https://onlinelibrary.wiley.com/doi/ book/10.1002/9783906390437

48. Acquah C, Stefano ED, Udenigwe CC. Role of hydrophobicity in food peptide functionality and bioactivity. J Food Bioact. 2018;4(1):88-98. DOI: https://doi.org/10.31665/JFB.2018.4164

49. Shultz MD. Two Decades under the Influence of the Rule of Five and the Changing Properties of Approved Oral Drugs. J Med Chem. 2019;62(4):1701-14. DOI: https://doi.org/10.1021/acs. jmedchem.8b00686

50. Alam A, Kowal J, Broude E, Roninson I, Locher KP. Structural insight into substrate and inhibitor discrimination by human P-glycoprotein. Science. 2019;363(6428):753-6. DOI: https://doi. org/10.1126/science.aav7102

51. Di L, Kerns EH. Drug-Like Properties - Concepts, Structure Design and Methods from ADME to Toxicity Optimization [Internet]. 2nd ed. Elsevier; 2016 [cited 2021 May 2]. 580 p. Available from: https:// linkinghub.elsevier.com/retrieve/pii/C2013018378X

52. Mulvihill EE, Varin EM, Gladanac B, Campbell JE, Ussher JR, Baggio LL, et al. Cellular Sites and Mechanisms Linking Reduction of Dipeptidyl Peptidase-4 Activity to Control of Incretin Hormone Action and Glucose Homeostasis. Cell Metab. 2017;25(1):152-65. DOI: https://doi.org/10.1016/j.cmet.2016.10.007

53. Kim MT, Sedykh A, Chakravarti SK, Saiakhov RD, Zhu H. Critical Evaluation of Human Oral Bioavailability for Pharmaceutical Drugs by Using Various Cheminformatics Approaches. Pharm Res. 2014;31(4):1002-14. DOI: https://doi.org/10.1007/s11095-013-1222-1

54. Isvoran A, Louet M, Vladoiu DL, Craciun D, Loriot M-A, Villoutreix $\mathrm{BO}$, et al. Pharmacogenomics of the cytochrome P450 2C family: impacts of amino acid variations on drug metabolism. Drug Discov Today. 2017;22(2):366-76. DOI: https://doi.org/10.1016/j. drudis.2016.09.015

55. Deodhar M, Rihani SBA, Darakjian L, Turgeon J, Michaud V. Assessing the Mechanism of Fluoxetine-Mediated CYP2D6 Inhibition. Pharmaceutics. 2021;13(2):148. DOI: https://doi. org/10.3390/pharmaceutics13020148

56. Smith DA, Beaumont K, Maurer TS, Di L. Relevance of Half-Life in Drug Design. J Med Chem. 2018;61(10):4273-82. DOI: https:// doi.org/10.1021/acs.jmedchem.7b00969

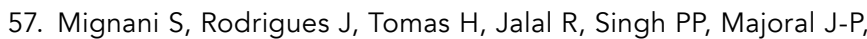
et al. Present drug-likeness filters in medicinal chemistry during the hit and lead optimization process: how far can they be simplified? Drug Discov Today. 2018;23(3):605-15. DOI: https:// doi.org/10.1016/j.drudis.2018.01.010

58. Teague SJ, Davis AM, Leeson PD, Oprea T. The Design of Leadlike Combinatorial Libraries. Angew Chem Int Ed. 
1999;38(24):3743-8. DOI: https://doi.org/10.1002/(SICI)1521 3773(19991216)38:24<3743::AID-ANIE3743>3.0.CO;2-U

59. Ertl P, Schuffenhauer A. Estimation of synthetic accessibility score of drug-like molecules based on molecular complexity and fragment contributions. J Cheminformatics. 2009;1(1):8. DOI: https://doi.org/10.1186/1758-2946-1-8

60. Azad I, Nasibullah M, Khan T, Hassan F, Akhter Y. Exploring the novel heterocyclic derivatives as lead molecules for design and development of potent anticancer agents. J Mol Graph Model. 2018;81(1):211-28. DOI: https://doi.org/10.1016/j. jmgm.2018.02.013

61. Iwaniak A, Minkiewicz P, Pliszka M, Mogut D, Darewicz M. Characteristics of Biopeptides Released In Silico from Collagens Using Quantitative Parameters. Foods. 2020;9(7):965. DOI: https:// doi.org/10.3390/foods9070965

62. Kyselova A, Elgheznawy A, Wittig I, Heidler J, Mann AW, Ruf W, et al. Platelet-derived calpain cleaves the endothelial protease- activated receptor 1 to induce vascular inflammation in diabetes. Basic Res Cardiol. 2020;115(6):75. DOI: https://doi.org/10.1007/ s00395-020-00833-9

63. Dókus LE, Yousef M, Bánóczi Z. Modulators of calpain activity: inhibitors and activators as potential drugs. Expert Opin Drug Discov. 2020;15(4):471-86. DOI: https://doi.org/10.1080/174604 41.2020.1722638

64. Donkor IO. An update on the therapeutic potential of calpain inhibitors: a patent review. Expert Opin Ther Pat. 2020;30(9):65975. DOI: https://doi.org/10.1080/13543776.2020.1797678

65. Andrade EL, Bento AF, Cavalli J, Oliveira SK, Freitas CS, Marcon $\mathrm{R}$, et al. Non-clinical studies required for new drug development - Part I: early in silico and in vitro studies, new target discovery and validation, proof of principles and robustness of animal studies. Braz J Med Biol Res. 2016;49(11):e5644. DOI: https://doi. org/10.1590/1414-431X20165644 